\title{
ANALISA LINK BUDGET DENGAN PERBANDINGAN PEMODELAN PROPAGASI PADA KOMUNIKASI BERGERAK DAERAH URBAN
}

\section{LINK BUDGET ANALYSIS WITH COMPARISSON OF PROPAGATION MODELING IN MOBILE COMMUNICATION URBAN AREA}

\author{
Monica Pasu Aprilia Simarmata ${ }^{1}$, Sopian Soim ${ }^{2}$ Mohammad Fadhli ${ }^{3}$ \\ ${ }^{123}$ Jurusan Teknik Elektro, Politeknik Negeri Sriwijaya \\ ${ }^{1}$ monicapriliss@gmail.com, ${ }^{2}$ sopian_soim@ polsri.ac.id, ${ }^{3}$ mohammad.fadhli@polsri.ac.id
}

\begin{abstract}
Abstrak
Peranan penting pada perhitungan link budget agar dapat membangun kualitas yang baik dalam sistem komunikasi. Penelitian ini dilakukan dengan adanya perhitungan serta pengukuran RSL, kedua data yang telah diperoleh akan dianalisis dan dapat ditentukan model propagasi yang tepat untuk diimplementasikan di daerah urban kota Palembang. Penelitian ini menggunakan model PCS Extension to Hata dan model SUI dalam perhitungan path loss dan menggunakan metode drive test dengan aplikasi G-Net Track pada pemerolehan data pengukuran. Rentang jarak dalam penelitian ini berkisar 500 - $1500 \mathrm{~m}$ dan berlokasi di 5 site berbeda. Berdasarkan hasil penelitian ini, hasil pengukuran RSL dari kelima site yang memiliki selisih paling sedikit dengan hasil perhitungan RSL adalah model SUI, seperti pada site 1 RSL pengukuran sebesar $-88 \mathrm{dBm}$, hasil perhitungan RSL model SUI sebesar -89.4141 dBm dan model PCS Extension to Hata sebesar $-92.4909 \mathrm{dBm}$. Maka model propagasi yang tepat digunakan pada daerah urban yang telah dievaluasi adalah model SUI. Pernyataan ini diperkuat berdasarkan hasil rata-rata persentase error yakni model propagasi SUI sebesar 3,4078 \% dan memiliki error yang lebih kecil dibandingkan dengan model propagasi PCS Extension to Hata sebesar 4,263\%.
\end{abstract}

\section{Kata kunci : Path loss, RSL, Link Budget, PCS Extension to Hata, SUI}

\begin{abstract}
The important role in link budget calculation is to be able to build good communication system. This research was conducted with the calculation and measurement of RSL, the result will be analyzed and can be determined the appropriate propagation model to be implemented in urban area of Palembang. This research used PCS Extension to Hata model and SUI model in path loss calculation and used drive test method with G-Net Track in acquisition of measurement data. The distance range specified in $500-1500 \mathrm{~m}$ and located on 5 different sites. Based on this research, the RSL measurement results from the five sites have the least difference with the results of RSL SUI model calculations, such as at site 1 RSL measurement of $-88 \mathrm{dBm}$, the RSL model calculation of the SUI is $-89,4141 \mathrm{dBm}$ and the PCS Extension to Hata model is $-92,4909 \mathrm{dBm}$. So the right propagation model used in urban areas that has been evaluated is the SUI model. This statement is strengthened by the results of the average error percentage that is the SUI propagation model of $3.4078 \%$ and has a smaller error compared to the PCS Extension to Hata propagation model of $4.263 \%$.
\end{abstract}

Keywords : Path loss, RSL, Link Budget, PCS Extension to Hata, SUI 


\section{PENDAHULUAN}

Pada perancangan komunikasi seluler bergerak dibutuhkan perhitungan anggaran daya (link budget) guna menjaga kualitas jaringan komunikasi agar tetap pada hasil yang maksimal. Hal ini dikarenakan adanya perbedaan antara sinyal yang diterima dengan sinyal yang dipancarkan, terdapat pada semua sistem komunikasi akibat dari hambatan transmisi [1]. Data yang diperoleh dalam perhitungan link budget yakni nilai level sinyal penerima (Receive Signal Level / RSL) yang diperoleh dari perhitungan dengan parameter path loss.

Agar mencapai hasil yang maksimal dalam menentukan model propagasi yang akurat, dilakukan perbandingan antar model di suatu daerah tertentu. Diperlukan suatu pengukuran langsung ke lapangan untuk mendapatkan data propagasi, setelah data propagasi didapat dan diolah sedemikian rupa, maka menghasilkan sebuah pemodelan (model propagasi) [2]. Penelitian ini berada di daerah urban yang merupakan daerah perkotaan dengan kepadatan penduduk tinggi dan fitur manusia besar dibandingkan dengan daerah sekitarnya [3]. Kota Palembang menjadi daerah urban pada penelitian ini karena kota Palembang memiliki berbagai macam bangunan-bangunan tinggi.

Pada penelitian ini, data pengukuran diperoleh dengan metode drive test dengan menggunakan software G-Net Track yang terpasang pada handphone berbasis android. Drive test merupakan suatu cara untuk mengoptimasi jaringan radio dengan mengumpulkan informasi jaringan di lapangan secara real [4]. Hasil penelitian link budget dengan kedua pemodelan ini dapat dilihat dan dibandingkan melalui tabel komparasi dan grafik sebagai hasil perhitungan dan pengukuran, kemudian hasil tersebut dapat disimpulkan dan ditentukan pemodelan propagasi yang sesuai untuk diimplentasikan. Sehingga tercapailah tujuan pada penelitian ini yakni mengefisiensi nilai path loss dengan menggunakan kedua pemodelan propagasi di daerah urban dan mengetahui model propagasi yang paling akurat diimplementasikan di daerah urban. Sehingga penelitian ini dapat berguna bagi praktisi bidang telekomunikasi untuk merancang saluran transmisi yang baru dengan perhitungan model propagasi yang tepat diimplementasikan di daerah urban Palembang.

\section{DASAR TEORI DAN PERANCANGAN PENELITIAN}

\subsection{Model PCS Extension to Hata}

Rumus path loss model PCS Extension to Hata dijelaskan pada Persamaan (1) [5].

$L_{50}($ perkotaan $)=46,3+33,9 \log f_{c}-13,82 \log h_{t e}-a\left(h_{r e}\right)+\left(44,9-6,55 \log h_{t e}\right) \log d+C_{M}$

Berikut Persamaan (2) (3) (4) untuk menentukan nilai a $\left(\mathrm{h}_{\mathrm{re}}\right)[6]$.

Kota sedang

$$
a\left(h_{r e}\right)=\left(1,1 \log f_{c}-0,7\right) h_{r e}-\left(1,561 \log f_{c}-0,8\right) d B
$$

Kota besar, $\mathrm{f}_{\mathrm{c}} \leq 300 \mathrm{MHz}$

Kota besar, $\mathrm{f}_{\mathrm{c}} \geq 400 \mathrm{MHz}$

$$
\mathrm{a}\left(\mathrm{h}_{\mathrm{re}}\right)=8,29\left[\log \left(1,54 \mathrm{~h}_{\mathrm{re}}\right)\right] 2-1,1 \mathrm{~dB}
$$

$$
\mathrm{a}\left(\mathrm{h}_{\text {re }}\right)=3,2\left[\log \left(11,54 \mathrm{~h}_{\text {re }}\right)\right] 2-4,97 \mathrm{~dB}(4)
$$

Terdapat batasan-batasan pada parameter model propagasi ini, yakni:

$\mathrm{f}_{\mathrm{c}} \quad=900 \mathrm{MHz}$ hingga $2000 \mathrm{MHz}$

$\mathrm{h}_{\mathrm{te}} \quad=30$ meter hingga 200 meter

$\mathrm{h}_{\mathrm{re}} \quad=1$ meter hingga 10 meter

d $\quad=1 \mathrm{Km}$ hingga $20 \mathrm{Km}$ 
$\mathrm{C}_{\mathrm{M}}=0 \mathrm{~dB}$ (pinggiran kota) dan $3 \mathrm{~dB}$ (metropolitan)

\subsection{Model SUI (Stanford University Interim)}

Model propagasi SUI merupakan model yang direkomendasikan untuk standar IEEE 802.16a yang cocok diterapkan di wilayah urban Indonesia [7].

$$
\mathrm{PL}=\mathrm{A}+10 \gamma \log _{10}\left(\frac{d}{d 0}\right)+\mathrm{X}_{\mathrm{f}}+\mathrm{X}_{\mathrm{hCPE}}+\mathrm{s}
$$

Dimana:

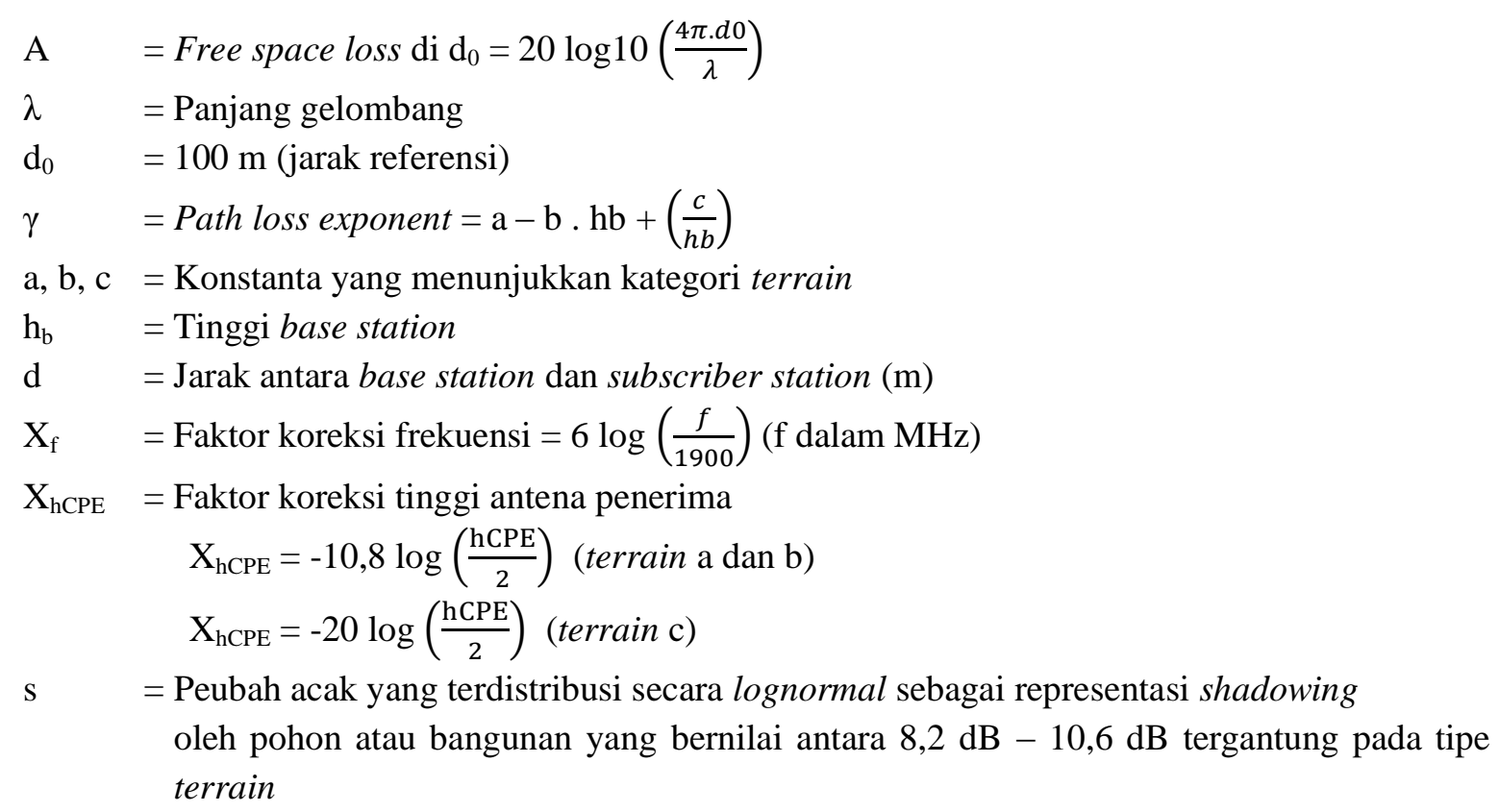

Tabel 1. Parameter Terrain [8]

\begin{tabular}{|c|c|c|c|}
\hline Model Parameter & $\begin{array}{c}\text { Tipe A } \\
\text { (Heavy Multipath) }\end{array}$ & $\begin{array}{c}\text { Tipe B } \\
\text { (Intermediate Multipath) }\end{array}$ & $\begin{array}{c}\text { Tipe C } \\
\text { (Few Multipath) }\end{array}$ \\
\hline a & 4,6 & 4 & 3,6 \\
\hline b & 0,0075 & 0,0065 & 0,005 \\
\hline c & 12,6 & 17,1 & 20 \\
\hline $\begin{array}{c}\text { Shadowing Margin } \\
\text { (dB) }\end{array}$ & 10,6 & 9,4 & 8,2 \\
\hline
\end{tabular}

\subsection{Link Budget}

Adapun parameter-parameter pada perhitungan link budget yakni propagasi gelombang radio guna memprediksi rugi-rugi propagasi pengirim dan penerima, daya pancar transmisi, penguatan antena, sensitifitas penerima, dan margin [9], serta menghubungkan kinerja (performance) yang diinginkan dengan tingkat sinyal penerima. RSL merupakan level sinyal yang diperoleh penerima serta memiliki nilai yang lebih besar dari sensitifitas perangkat penerima (RSL $\geq$ Rth). Beberapa buku ataupun penelitian RSL juga biasa disebut RSRP (Reference Signal Received Power). Rumus untuk menghitung RSL / RSRP dapat diliat pada Persamaan (7) [5].

$$
\mathrm{EIRP}=\mathrm{P}_{\mathrm{t}}+\mathrm{G}_{\mathrm{t}}-\text { Loss system }
$$


Dimana:
$\mathrm{EIRP}=$ Effective Isotropic Radiate Power $(\mathrm{dBm})$
$\mathrm{P}_{\mathrm{t}} \quad=$ Daya pancar $\mathrm{T}_{\mathrm{x}}(\mathrm{dBm})$
$\mathrm{G}_{\mathrm{t}} \quad=$ Penguatan antena $\mathrm{T}_{\mathrm{x}}(\mathrm{dB})$
Loss $\quad=$ Loss konektor $\mathrm{T}_{\mathrm{x}}(\mathrm{dB})$

Tabel 2. Parameter Analisis Nilai RSL/RSRP [10]

\begin{tabular}{|c|c|}
\hline Nilai & Keterangan \\
\hline$>=-71 \mathrm{dBm}$ & Sangat Baik \\
\hline$-72 \mathrm{dBm} \mathrm{s} / \mathrm{d}-81 \mathrm{dBm}$ & Baik \\
\hline$-82 \mathrm{dBm} \mathrm{s} / \mathrm{d}-91 \mathrm{dBm}$ & Normal \\
\hline$-92 \mathrm{dBm} \mathrm{s} / \mathrm{d}-101 \mathrm{dBm}$ & Buruk \\
\hline$<-102 \mathrm{dBm}$ & Sangat Buruk \\
\hline
\end{tabular}

\subsection{Perancangan Penelitian}

Gambar 1 menunjukkan kerangka tahapan penelitian yang tertera pada blok diagram sistem secara keseluruhan. Blok diagram ini memiliki peranan penting dalam perancangan penelitian, dimana melalui blok diagram dapat diketahui sistem kerja ataupun tahapan pada penelitian ini.

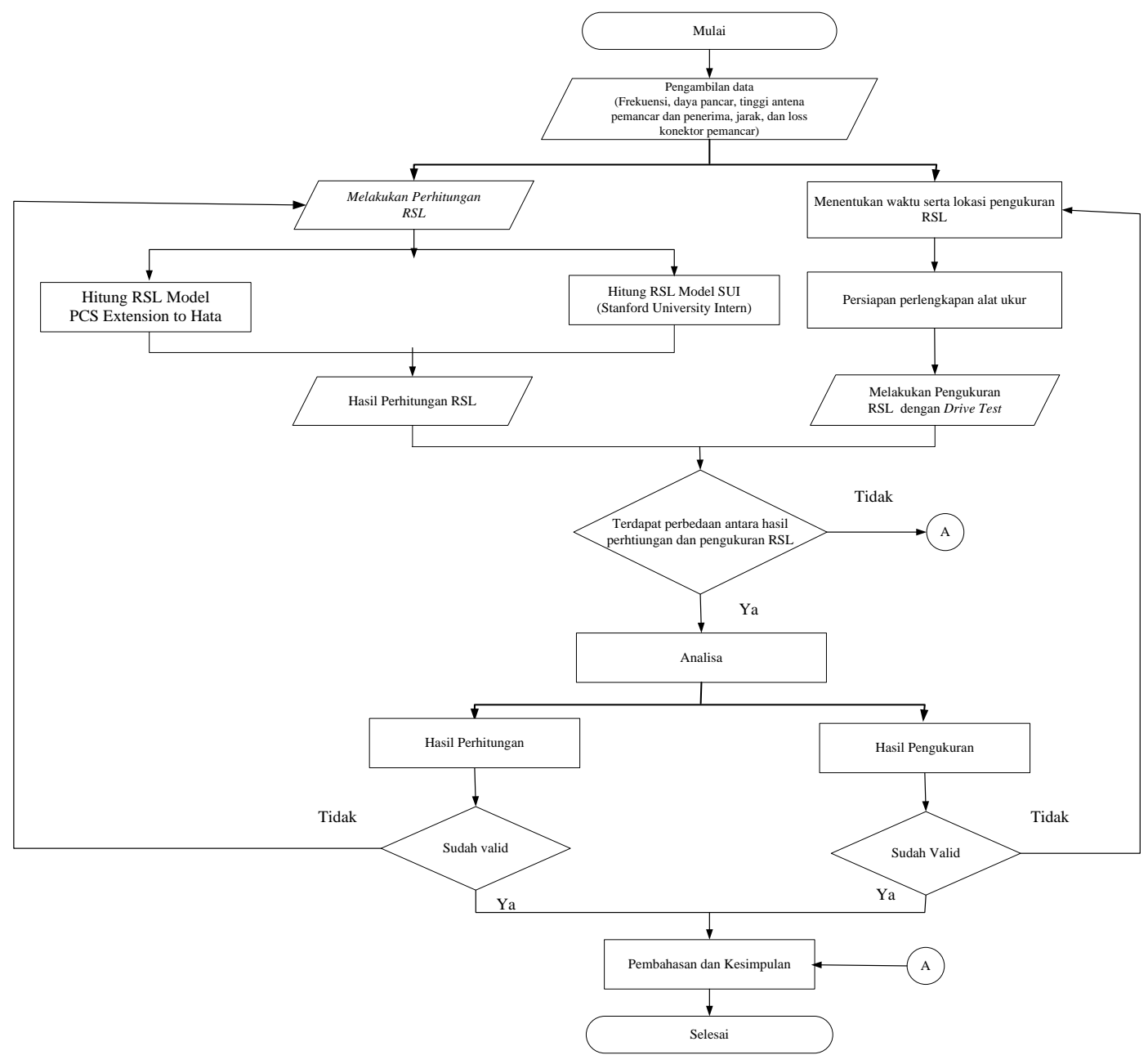

Gambar 1. Flowchart Perancangan Sistem Keseluruhan Penelitian 


\section{PEMBAHASAN}

\subsection{Skenario Pengukuran dan Perhitungan RSL}

Pengukuran RSL atau mengukur level daya yang diterima MS (Mobile Station) dengan gerakan mengelilingi dan menjauhi BTS. Jarak pengukuran yakni 500 meter hingga 1500 meter dengan rentang jarak antar titik yakni 100 meter. Parameter yang dibutuhkan dalam pengukuran yakni level daya terima fungsi jarak, frekuensi yang digunakan, serta area yang memenuhi kriteria daerah urban. Kegiatan dirve test pada kelima site dilakukan di hari yang berbeda namun memiliki waktu pengukuran yang sama, yakni pada pukul $15.00 \mathrm{~s} / \mathrm{d} 17.00 \mathrm{WIB}$.

Berikut kelima lokasi site yang menjadi tempat pengukuran:

1. Jl. Putri Rambut Selako Gg. Kolam Sikam Kel. Bukit Lama

2. Jl. Tj. Pandan, RT. 07, RW. 01, Suka Maju, Sako

3. Jl. HBR Motik Kp. Minterejo KM.8, No. 1880, Karya Baru, Kec. Alang-Alang Lebar

4. Jl. Jendral Ahmad Yani, Gg. PU, 7 Ulu, Kec. Seberang Ulu 1

5. Jl. Bangau No. 40, 9 Ilir, Kec. Ilir Timur 2

Perhitungan nilai RSL diperoleh dengan persamaan (7), pemerolehan nilai path loss model PCS Extension to Hata menggunakan persamaan (1) dan model SUI menggunakan persamaan (5).

\subsection{Hasil Pengukuran dan Perhitungan RSL}

Hasil perhitungan dan pengukuran RSL ditampilkan pada tabel komparasi nilai RSL dari kedua pemodelan serta grafik yang diplot menggunakan software Matlab. Hasil data pengukuran dan perhitungan dikelompokkan berdasarkan masing-masing site. Tabel 3 merupakan tabel komparasi hasil pengukuran dan perhitungan RSL di 5 site daerah urban Palembang.

Tabel 3. Hasil Perhitungan dan Pengukuran RSL

\begin{tabular}{|c|c|c|c|}
\hline Jarak (m) & $\begin{array}{c}\text { Perhitungan RSL } \\
\text { Model PCS Extension to Hata } \\
(\mathrm{dBm})\end{array}$ & $\begin{array}{l}\text { Perhitungan RSL } \\
\text { Model SUI } \\
(\mathbf{d B m})\end{array}$ & Pengukuran RSL (dBm) \\
\hline \multicolumn{4}{|c|}{ SITE 1} \\
\hline 500 & -92.4909 & -89.4141 & -88 \\
\hline 600 & -95.2670 & -92.8434 & -89 \\
\hline 700 & -97.6141 & -95.7429 & -92 \\
\hline 800 & -99.6472 & -98.2546 & -93 \\
\hline 900 & -101.4406 & -100.4700 & -95 \\
\hline 1000 & -103.0448 & -102.4518 & -97 \\
\hline 1100 & -104.4960 & -104.2445 & -98 \\
\hline 1200 & -105.8208 & -105.8812 & -99 \\
\hline 1300 & -107.0395 & -107.3867 & -101 \\
\hline 1400 & -108.1679 & -108.7806 & -106 \\
\hline 1500 & -109.2184 & -110.0784 & -110 \\
\hline \multicolumn{4}{|c|}{ SITE 2} \\
\hline 500 & -85.1594 & -82.1378 & -81 \\
\hline 600 & -87.8728 & -85.4113 & -83 \\
\hline 700 & -90.1669 & -88.1790 & -86 \\
\hline 800 & -92.1541 & -90.5765 & -89 \\
\hline 900 & -93.9070 & -92.6912 & -92 \\
\hline 1000 & -95.4750 & -94.5829 & -93 \\
\hline 1100 & -96.8934 & -96.2941 & -95 \\
\hline 1200 & -98.1884 & -97.8563 & -97 \\
\hline 1300 & -99.3796 & -99.2934 & -98 \\
\hline 1400 & -100.4825 & -100.6240 & -100 \\
\hline 1500 & -101.5093 & -101.8627 & -101 \\
\hline \multicolumn{4}{|c|}{ SITE 3} \\
\hline
\end{tabular}


| ISSN (p) : 2407-1323 | ISSN (e) : 2442-4404

DOI : https://doi.org/10.25124/jett.v5i2.1989

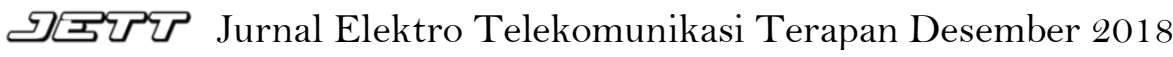

\begin{tabular}{|c|c|c|c|}
\hline 500 & -87.9976 & -84.9250 & -85 \\
\hline 600 & -90.7520 & -88.2990 & -87 \\
\hline 700 & -93.0808 & -91.1517 & -89 \\
\hline 800 & -95.0982 & -93.6227 & -91 \\
\hline 900 & -96.8776 & -95.8024 & -95 \\
\hline 1000 & -98.4693 & -97.7521 & -96 \\
\hline 1100 & -99.9092 & -99.5159 & -97 \\
\hline 1200 & -101.2237 & -101.1261 & -98 \\
\hline 1300 & -102.4330 & -102.6073 & -99 \\
\hline 1400 & -103.5526 & -103.9788 & -100 \\
\hline 1500 & -104.5949 & -105.2555 & -101 \\
\hline \multicolumn{4}{|c|}{ SITE 4} \\
\hline 500 & -86.0563 & -82.9969 & -84 \\
\hline 600 & -88.7958 & -86.3336 & -86 \\
\hline 700 & -91.1120 & -89.1549 & -88 \\
\hline 800 & -93.1184 & -91.5987 & -89 \\
\hline 900 & -94.8881 & -93.7543 & -90 \\
\hline 1000 & -96.4712 & -95.6826 & -91 \\
\hline 1100 & -97.9033 & -97.4270 & -92 \\
\hline 1200 & -99.2107 & -99.0194 & -94 \\
\hline 1300 & -100.4134 & -100.4843 & -95 \\
\hline 1400 & -101.5269 & -101.8406 & -97 \\
\hline 1500 & -102.5636 & -103.1033 & -98 \\
\hline \multicolumn{4}{|c|}{ SITE 5} \\
\hline 500 & -93.8467 & -90.7709 & -90 \\
\hline 600 & -96.6077 & -94.1614 & -91 \\
\hline 700 & -98.9420 & -97.0280 & -93 \\
\hline 800 & -100.9641 & -99.5112 & -95 \\
\hline 900 & -102.7478 & -101.7015 & -96 \\
\hline 1000 & -104.3433 & -103.6608 & -97 \\
\hline 1100 & -105.7866 & -105.4332 & -99 \\
\hline 1200 & -107.1042 & -107.0513 & -101 \\
\hline 1300 & -108.3164 & -108.5398 & -102 \\
\hline 1400 & -109.4386 & -109.9180 & -105 \\
\hline 1500 & -110.4834 & -111.2010 & -107 \\
\hline
\end{tabular}

Gambar 2 menunjukkan grafik hasil perhitungan dan pengukuran RSL di 5 site yang diplot menggunakan software Matlab.
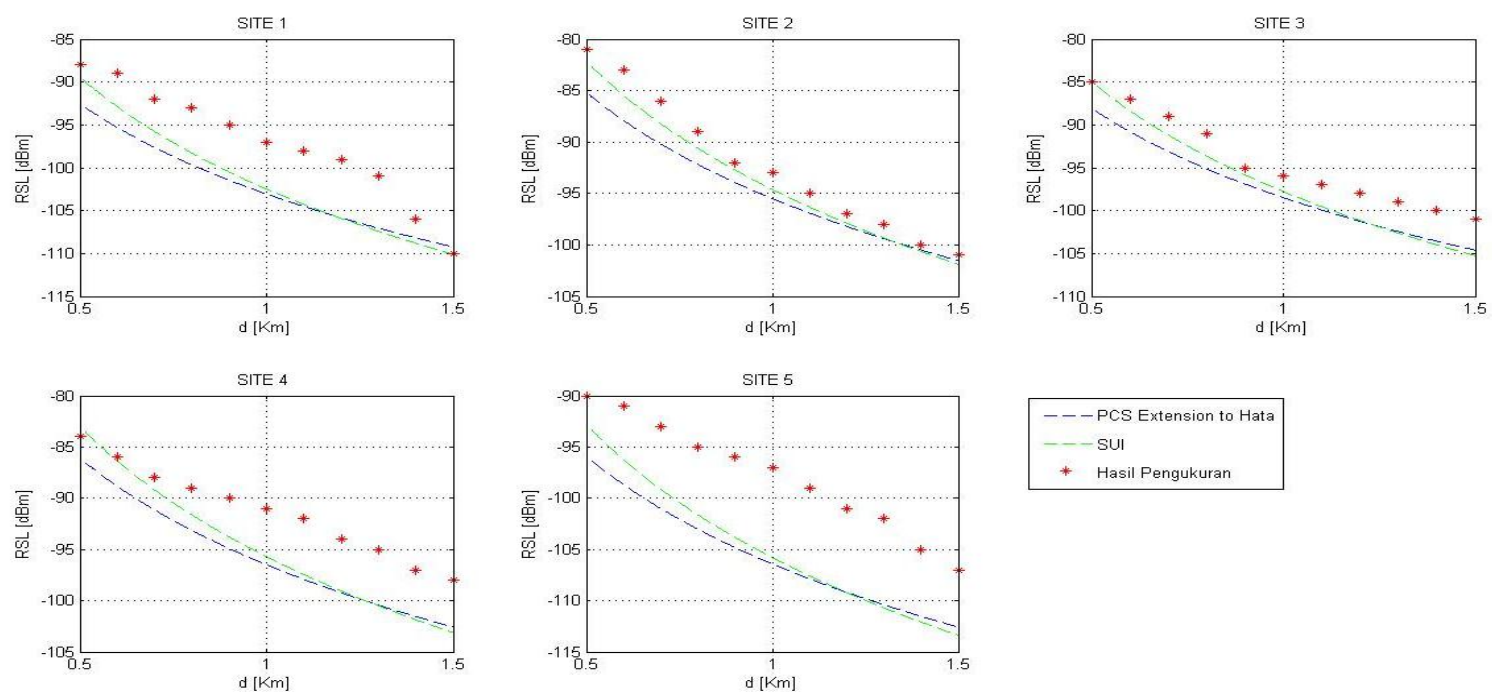

Gambar 2. Grafik Hasil Perhitungan dan Pengukuran RSL 
Karakteristik di tiap site pada tabel 4 diperoleh melalui data parameter link budget milik PT GCI Indonesia Palembang yang merupakan suatu perusahan subcontractor network installation. Pemerolehan data dan pengukuran langsung di lapangan telah memiliki izin dari pihak PT GCI Indonesia Palembang.

Tabel 4. Karakteristik di Lima Site

\begin{tabular}{|c|c|c|c|c|c|c|}
\hline Site & $\begin{array}{c}\text { Frekuensi Carrier } \\
(\mathrm{MHz})\end{array}$ & $\begin{array}{c}\text { Tinggi Antena } \\
\text { MS }(\mathrm{m})\end{array}$ & $\begin{array}{c}\text { Tinggi Antena BS } \\
(\mathrm{m})\end{array}$ & $\begin{array}{c}\text { Gain Antena } \\
(\mathrm{dBi})\end{array}$ & $\begin{array}{c}\mathrm{T}_{\mathrm{x}} \text { Power } \\
(\mathrm{dBm})\end{array}$ & $\begin{array}{c}\text { Diameter } \\
\text { Antena } \\
(\mathrm{m})\end{array}$ \\
\hline $\mathbf{1}$ & 900 & 1 & 31.8 & 34.5 & 20 & 0.6 \\
\hline $\mathbf{2}$ & 900 & 1 & 42 & 40.4 & 20 & 1.2 \\
\hline $\mathbf{3}$ & 900 & 1 & 35 & 38.5 & 20 & 0.9 \\
\hline $\mathbf{4}$ & 900 & 1 & 37.4 & 40.1 & 20 & 0.6 \\
\hline $\mathbf{5}$ & 900 & 1 & 32.6 & 31 & 20 & 0.6 \\
\hline
\end{tabular}

Pada grafik Gambar 2 dan tabel komparasi Tabel 3 hasil perhitungan dan pengukuran, keduanya menjelaskan bahwa semakin jauh jarak antara receiver dari transmitter maka nilai RSL yang diperoleh juga semakin kecil. Pada hasil perhitungan RSL, kedua model propagasi memiliki hasil penurunan logaritmik yang teratur secara berkala dan memiliki nilai selisih antar jarak yang sama besar, sedangkan untuk hasil pengukuran, selisih nilai RSL antar jarak tidak memiliki jumlah yang sama serta tidak mengalami penurunan logaritmik yang teratur secara berkala.

Bentuk grafik yang tidak tetap pada grafik hasil pengukuran disebabkan oleh beberapa faktor yang mempengaruhi kegiatan drive test pada tiap site, diantaranya karakteristik pada kelima site yang berbeda, hambatan-hambatan yang mengganggu jalur transmisi pada daerah urban di tiap site, seperti pengaruh cuaca yang meliputi kecepatan angin, kelembapan udara, intensitas cahaya matahari, dan keadaan awan, pepohonan, serta gedung-gedung tinggi seperti hotel, sekolah, tempat ibadah, juga terdapat lintasan LRT.

Site 2 dan 3 memiliki hasil perhitungan yang paling mendekati dengan hasil pengukuran, hal ini dikarenakan keadaan fisik wilayah pada site tersebut memungkinkan untuk keadaan LOS (Line of Sight), dimana pada wilayah tersebut merupakan daerah perumahan penduduk yang tidak terdapat banyak gedung-gedung tinggi dan berkaca dibanding site 1, 4, dan 5. Pada site 2 dan 3 memiliki karakteristik dengan diameter antena yang paling lebar yang memungkinkan semakin jauhnya jarak yang dapat dijangkau oleh antena dengan kualitas sinyal tetap baik, dibandingkan dengan site lainnya. Pengaruh cuaca juga menentukan pengaruh perbedaan hasil pengukuran dan perhitungan, pengukuran yang dilakukan pada site 2 dan 3 pada cuaca cerah, sedangkan pada site 1 , 4, dan 5 pada kondisi cuaca berawan dan berangin, kondisi tersebut memberi efek penurunan pada kualitas sinyal yang diterima pada saat pengukuran karena benturan gelombang di udara terhadap partikel air dan kecepatan angin mengakibatkan gelombang yang seharusnya berkualitas baik serta tepat sasaran menjadi pecah dan berbelok-belok.

Melalui tabel dan grafik hasil perhitungan dan pengukuran pada penelitian ini, dapat dilihat bahwa hasil perhitungan RSL menggunakan model PCS Extension to Hata dan model SUI memiliki selisih yang sedikit. Melalui hasil grafik juga dapat dilihat betuk grafik yang mendekati grafik hasil pengukuran adalah grafik hasil perhitungan RSL menggunakan model propagasi SUI. Hal ini membuktikan bahwa model propagasi SUI yang cocok untuk diimplementasikan di wilayah urban kota Palembang, pernyataan ini juga dapat diperkuat melalui hasil evaluasi RSL.

\subsection{Evaluasi RSL}

Persentase error yang diperoleh pada masing-masing site, yakni:

1. SITE 1 = Model PCS Extension to Hata sebesar 5,267\% dan Model SUI sebesar 4,452\%.

2. SITE $2=$ Model PCS Extension to Hata sebesar 2,580\% dan Model SUI sebesar 1,429\%. 
3. SITE 3 = Model PCS Extension to Hata sebesar 3,467\% dan Model SUI sebesar 2,509\%.

4. SITE $4=$ Model PCS Extension to Hata sebesar 4,787\% dan Model SUI sebesar 3,725\%.

5. SITE $5=$ Model PCS Extension to Hata sebesar 5,816\% dan Model SUI sebesar 4,924\%.

Nilai persentase error menunjukkan besarnya error yang tedapat pada hasil perhitungan dan pengukuran. Rata-rata nilai persentase error di kelima site pada model propagasi PCS Extension to Hata sebesar 4,263\% dan model propagasi SUI sebesar 3,4078 \%. Nilai ini menunjukkan bahwa model propagasi SUI yang cocok untuk diimplementasikan pada daerah urban. Tujuan dari mengevaluasi RSL melalui nilai persentase error yakni menunjukkan tingkat kesesuaian terhadap nilai pengukuran dan perhitungan yang telah tertera pada Tabel 3, dimana model propagasi dengan nilai persentase error terkecil menunjukkan bahwa model propagasi tersebut paling cocok untuk diterapkan di daerah urban.

\section{KESIMPULAN}

Berdasarkan hasil penelitian ini, maka dapat disimpulkan bahwa model propagasi yang cocok diimplementasikan pada daerah urban adalah model SUI. Hal ini dilihat melalui tabel komparasi pada Tabel 3 dan grafik Gambar 2 yang menunjukkan hasil perhitungan RSL menggunakan model SUI tidak jauh berbeda dengan hasil pengukuran. Serta berdasarkan nilai persentase error model SUI pada kelima site yang selalu lebih rendah dibandingkan dengan nilai persentase error model PCS Extension to Hata.

Model propagasi PCS Extension to Hata juga merupakan model propagasi yang diterapkan pada wilayah urban, meskipun pada penelitian ini model SUI merupakan model yang paling tepat untuk wilayah urban kota Palembang. Hasil pengukuran dan perhitungan model PCS Extension to Hata juga tidak memiliki nilai yang terlampau jauh berbeda. Sehingga disimpulkan bahwa model PCS Extension to Hata dapat dijadikan alternatif lain pada perhitungan path loss dalam perencanaan link transmisi baru daerah urban lainnya.

Diharapkan tercapainya tujuan penelitian ini, agar dapat membantu para teknisi telekomunikasi yang ingin membangun perencanaan link transmisi baru di kota Palembang dengan menggunakan perhitungan model propagasi SUI.

\section{DAFTAR PUSTAKA}

[1] Stallings, William. 2009. Komunikasi dan Jaringan Nirkabel. Jakarta: Penerbit Erlangga.

[2] Purnamirza, Teddy; Yuhrijul; Rahmi, Depriwana. 2014. Model Propagasi untuk Kanal Radio Bergerak pada Frekuensi 900 MHz di Kota Pekanbaru. Jurnal Sitekin. Vol 12, No 1(2014).

[3] Nindito, Satrio; Siswandari, Nur Adi; Puspitorini, Okkie. 2013. Analisa Pathloss Exponent pada Daerah Urban dan Suburban. Prosiding SNaPP. Vol 2, No 1(2011).

[4] Pramulia, I Putu Dedy Krisna. 2015. Analisis Pengaruh Jarak Antara User Equipment dengan EnodeB Terhadap Nilai RSRP (Reference Signal Received Power) pada Teknologi LTE 900 MHz. Skripsi. Bali: Universitas Udayana.

[5] Sunomo. 2004. Pengantar Sistem Komunikasi Nirkabel. Jakarta: PT Grasindo.

[6] Mark, Jon W. dan Weihua Zhuang. 2008. Wireless Communications and Networking. New Delhi: PHI Learning Private Limited.

[7] Pramono, Catur; Santoso, Imam; Isnanto, R. Rizal. 2011. Pemodelan Kanal SUI pada Sistem Komunikasi WiMAX. Makalah. Semarang: Universitas Dipenogoro.

[8] Manalu, Ria Oktavia. 2016. Perbandingan Model Empiris Propagasi Pathloss Guna Estimasi RugiRugi Lintasan Antena Radar di Perum LPPNPI Indonesia. Skripsi. Palembang: Politeknik Negeri Sriwijaya. 
[9] Sarjudin, Zulkha; Santoso, Imam; Zahra, Ajub A. 2012. Simulasi Link Budget pada Komunikasi Selular di Daerah Urban dengan Metode Walfisch Ikegami. Semarang: Universitas Dipenogoro.

[10] Wahyudin, Ade; Sakinah. 2016. Perancangan dan Analisa Penggelaran LTE pada Frekuensi 700 $\mathrm{MHz}$ dengan Metode Adaptif Modulation Coding untuk Implementasi Digital Dividend di Wilayah Sub-Urban dan Rural Kabupaten Banyumas. Jurnal JETT. Vol 3, No 2 (2016). 